\title{
Integration house of risk and analytical network process for supply chain risk mitigation of cassava opak chips industry
}

\author{
Nurul Ummi ${ }^{1, \mathrm{a}}$, Putro Ferro Ferdinant, Ade Irman M.S and Akbar Gunawan \\ ${ }^{1}$ Majoring in Industrial Engineering Universitas Sultan Ageng Tirtayasa, Jendral Sudirman Km. 3 \\ Cilegon, 42435, Indonesia
}

\begin{abstract}
Supply chain risk is difficult to predict and cause losses that will affect business growth. Supply chain management is a method used for risk control by being used in the cassava industry supply chain. This objective is to determine the risks that will occur and potentially disrupt the supply chain, to determine the risk agent sequence from the Aggregate Risk Potential (ARP) score, and to determine priority mitigation actions. This study uses integration methods. (HOR), and Analytic Network Process (ANP) with pareto diagrams and method-based ratings. The SCOR method is used to map supply chain activities and classify supply chain activities. Meanwhile, the HOR method is used in identifying risk events and risk agents, as well as assessments based on the assessment of the FMEA method. The output of the HOR method is the ARP score used for the priority of the risk agent. Pareto diagrams are used in the priority of risk agents that must be immediately addressed based on the ARP score. The ANP method is used to determine the priority of mitigation actions. Based on this study, researchers obtained 21 risk events and 30 risk agents with 17 risk agents including priority risk agents and 13 non-priority risk agents, and 10 mitigation measures.
\end{abstract}

\section{Introduction}

Opak Singkong is a traditional snack similar to chips which is very popular, made from thin circular boiled cassava with crisp texture. Opak Singkong has been a source of livelihood for the people of refined cassava craftsmen. This business is classified as a type of home industry.

The demand for Opak Singkong chips is quite high, but the processing is still conventional and the risk of processing failure causes the demand for Opak Singkong chips has not all been fulfilled. To meet the high and fluctuating demand for Opak Singkong chips, adequate supply chain management is needed.

\footnotetext{
${ }^{\text {a }}$ Corresponding author : Nurul.ummi@untirta.ac.id
} 
The supply chain includes all activities related with the effort to meet consumer needs, both directly and indirectly [1]. A good supply chain management will affect the process chain in creating value of products both in terms of cost efficiency and speed in meeting consumer needs (responsiveness Effective supply chain management is characterized by high demand fulfillment rates, always on time deliveries and efficient operating and sales expenses. The supply chain is a network of companies that work together to create and deliver a product to the endusers [2].

The development of supply chain management concept spawned a special concern of the risk impacts of a supply chain within the company. Every supply chain activity has the potential to face risks. This risk is a factor that hinders operations in the supply chain, where the risk in the supply chain can occur from the upstream suppliers, factories, distributors, consumers.

In the context of the supply chain, increased risk is part of the network complexity as a result of outside sources of the company. A study from [3] states that networks between organizations can increase company risk factors, especially when dealing with small and medium business partners. While according to supply chain risk is classified into operating risk and risk of interference [4]. The level of dependence and complexity of the supply chain network today makes the supply chain as a whole more vulnerable to disruption. Any interference that occurs in one of the supply chain players can affect the supply chain network as a whole, such as the cessation of information and resources from upstream to downstream in the supply chain. This can cause an imbalance between supply and demand. Therefore, risks in the supply chain can be defined as disruption of information and resource flows in supply chain networks due to uncertain terminations and variations [5]. Concerning the issue of potential risk deviations that occur in the entire series of production processes and mitigation management such as supply management, demand management, production management, information.

Management and safety management [6]. Supply chain risk management focuses on how to understand and overcome chain effects when small or large risks occur in supply chain networks. Furthermore, ensuring that when the risk occurs, supply chain players have the cability to return to normal conditions and continue their business [7]. Supply chain risk management consists of risk identification, risk analysis, risk evaluation and risk mitigation. Risk identification is a fundamental step in the risk management process [8] [9] SCOR is a reference model of supply chain operations. The SCOR model is basically a process-based model [10]. This model integrates three main elements in management, namely business process reengineering, benchmarking, and process measurement into the cross-functional framework in the supply chain. The SCOR model divides supply chain processes into five core processes, namely plan, source, make, deliver, and return [2].

The House of Risk (HOR) method is a supply chain risk management model using the concept of House of Quality and Failure Modes and Effects Analysis (FMEA) to develop a framework for managing supply chain risk [11]. HOR is a method for managing risk proactively, where the risk agent identified as the cause of risk event can be managed by determining priorities based on the magnitude of the impact that may be caused.

There exist many studies in Risk supply chain i.e. Hadiguna [12] Risk Assessment Model Based on Performance for Sustainable Palm Oil Supply Chain in Indonesia with Non Numeric Multi Criteria Decision Making Approach. Ulfah [13] Refined Sugar Supply Chain Risk Management With a House Of Risk Approach. Pujawan [11] Supply chain house of risk : a model risk management for proactive supply chain. Ummi et al [14] Risk identification Supply Chain in Banten Typical Foods With House Of Risk Method

The analytical network process (ANP), as an extensive and complementary method of the AHP, was introduced and further developed by Saaty $[15,16,17,18,19,20,21,22]$. The ANP method can be used to make decisions that cannot be arranged hierarchically and do 
not have independent assumptions. Since its introduction, the ANP method has been applied to various fields. For example, Lee and Kim [23] suggest an information system project (IS) method that uses ANP in a modeling model to solve IS project selection problems. Hafeez et al. [24] provides a structured framework to determine company capabilities using ANP. Karsak et al. [25] use ANP to evaluate the relationship between customer expectations and product technical requirements (PTR) to determine the level of quality at home PTR (HOQ).

Niemira and Saaty [26] developed a model of problem mismatch to estimate the possibility of financial problems based on the ANP framework. Chung et al. [27] use ANP to select and evaluate different products in electronic assemblers. Kahraman et al. [28] uses ANP to get the same objective function and propose a fuzzy optimization design for quality use planning (QFD) using ANP. Bayazit and Karpak [29] developed an ANP-based framework to assess total quality management (TQM). Aktar and Ustun [30] conduct integrated planning from Archimede and Goal Programming (AGP) and Analytic Network Process (ANP) to assess suppliers and determine their futures delivery locations with a number of appropriate and inappropriate criteria. Caballero-Luque et al. [31] presents ANPbased models to help managers work to clarify whether their site content is appropriate to meet the goals they have run. In addition to the above fields, ANP has also been widely used in risk evaluation and assessment analysis. Dagdeviren et al. [32] uses ANP to determine the significant risk of wrong behavior (FBR) in surviving work In ANP, having similarities with AHP, two priority issues need to be solved for the reciprocal pairwise comparison matrix (RPCM here after): test consistency and identification and similarity of inconsistent elements. However, this problem is more difficult in ANP than in AHP because there are many comparison matrices in ANP. There are many studies in consistency tests $[33,34,35,36,37,38,39,40]$. The most well-known consistency index for the pairwise comparison matrix in AHP / ANP is the ratio of consistency by Saaty. That is, $\mathrm{CR}=\mathrm{CI} / \mathrm{RI}<0.1$, where the consistency index $\mathrm{CI}=(\lambda \max -\mathrm{n}) /(\mathrm{n}-1), \mathrm{RI}$ is an average random index based on the size of the matrix $\mathrm{n}$, and $\lambda$ max is the maximum eigenvalue of the matrix A [36]. If CR is less than 0.1 , the comparison matrix calculates consistency tests. Otherwise, entries in the comparison matrix for which the same value must be revised. For element identification methods that are less consistent, this method does not have a generally accepted method for AHP / ANP. In the AHP Expert Choice software, the error matrix $\varepsilon \mathrm{ij}=$ aij (wj / wi) is built to assess the elements that are least in line with expectations [18]

When ANP is used to evaluate and analyze risk factors and possible risks, as well as the impact of the decision results for events that arise, constant comparison matrix and elements that are not constant must be known and adjusted. Risk identification and decision analysis of the circumstances that arise are important time-critical information services that are highly dependent on time and information

\section{Experimental programs}

This paper proposes the integration of HOR into ANP method for Supply Chain Risk Mitigation Cassava Opak Chips. HOR by using Failure Modes and Effect Analysis (FMEA), used to determine the severity of risk events and the emergence probability of risk causes, and the ANP Method is used to determine risk mitigation actions based on a priority scale. Based on the order of priorities can be determined proactive and effective steps to reduce the possibility of risks. The following are steps for integrating HOR and ANP:

1. Mapping of supply chain activities based on the SCOR method

2. Identification of supply chain risks based on SCOR classification 
This stage includes identifying risks that might occur and potentially occur in supply chain activities. One important aspect that will be carried out in identifying risks is to list the risks that may occur as much as possible by means of field surveys, interviews and questionnaires (Ulfah, 2016).

3. Risk Measurement

Assess the impact (severity) of such risk event (if happened). We use a 1-10 scale where 10 represents extremely severe or catastrophic impact (see Shahin (2004) for a detailed verbal description about the scale). Identify risk agents and assess the likelihood of occurrence of each risk agent. Here, a scale of 1-10 is also applied where 1 means almost never occurred and a value of 10 means almost certain to happen. Develop a relationship matrix, i.e. relationship between each risk agent and each risk event, Rij $\{0,1,3,9\}$ where 0 represents no correlation and 1, 3, and 9 represent, respectively, low, moderate, and high correlations.

4. Calculating Aggregate Risk Potential (ARPj) is determined by the possibility of a risk agent and aggregate the impact of the risk event generated.

$$
A R P_{j}=O_{j} \sum S_{j} R_{i j}
$$

If $\mathrm{Oj}$ is the probability of occurrence of risk agent $\mathrm{j}, \mathrm{Si}$ is the severity of impact if risk event $\mathrm{i}$ occurred, and Rij is the correlation between risk agent $\mathrm{j}$ and risk event $\mathrm{I}$, than ARPj Aggregate Risk Potential of Risk agent $\mathrm{j}$.

5. Creating a risk agent priority based on the aggregate risk potential (ARP)

6. Risk Mitigation Stage

7. This stage uses the ANP method to mitigate risks and reduce the consequences of risks and prioritize risk control follow-up. The stages that must be carried out in the ANP method are as follows:

a. Create a decision network hierarchy that shows the relationship between decision factors

b. Form a pairwise comparison matrix between factors that influence decisions. This pairwise comparison matrix is needed to calculate the impact on alternatives compared to the 1-9 measurement ratio scale developed by Saaty.

c. Calculate relative importance weight vectors

The level of inconsistency in the response is called the inconsistency ratio (CR). The steps in calculating $\mathrm{CR}$ are as follows:

a)Pairwise comparison value multiplied by the weighting matrix (eigen) resulting in a value of the results. The results values will then be divided by the eigenvalues of each row to get an average value. Then calculate the value of $\lambda$ max.

b)The value of $\lambda$ max is obtained from the number of results divided by the number of indicators compared

$$
\lambda \max =\frac{\text { number of yield values }}{\text { number of indicators }}
$$

c)Consistency index (CI) is derived from the calculation of the value of $\lambda \max$ minus the number of indicators, then divided the number of indicators minus 1 .

d)Consistency Ratio (CR)

$$
\mathrm{CR}=\frac{\mathrm{CI}}{\text { Random Index }}
$$

Saaty (1994) proposed the maximum allowable inconsistency ratio is 0.10 or $10 \%$. 
d. Supermatrix establishment and analysis. Supermatrix is a matrix composed of relative importance weight vectors. Then normalize the supermatrix so that the numbers in each column in the matrix have a value of 1 (one).

e. Calculation of the final weight to determine the importance of each subcriteria.

\section{Results and discussions}

Based on the results of clarification with the company, we found total of 21 risk events with their representative degree of severity, and total of 30 risk agents with their respective degree of occurrence. The next step we can calculate the aggregate risk potentials of each risk agent. The relationships between each risk agent and each risk event is shown in HOR1 in Table 2.

As can be seen from Table 2, the calculated values range from 35 to 441 . The Pareto diagram of the aggregate risk potentials for all 21 risk events is shown in Figure 1. From the Pareto analysis shows that the first seventeen risk agents contribute to about 81,57 percent of the total commulative ARP values and it should be prioritize for reduction those with high-aggregate risk potentials, and 13 risk agents contribute to 18,43 percent of the total commulative ARP value are not prioritize for reduction.

Table 1. Some of risk events and risk agent, with Severity and Occurrence Degree

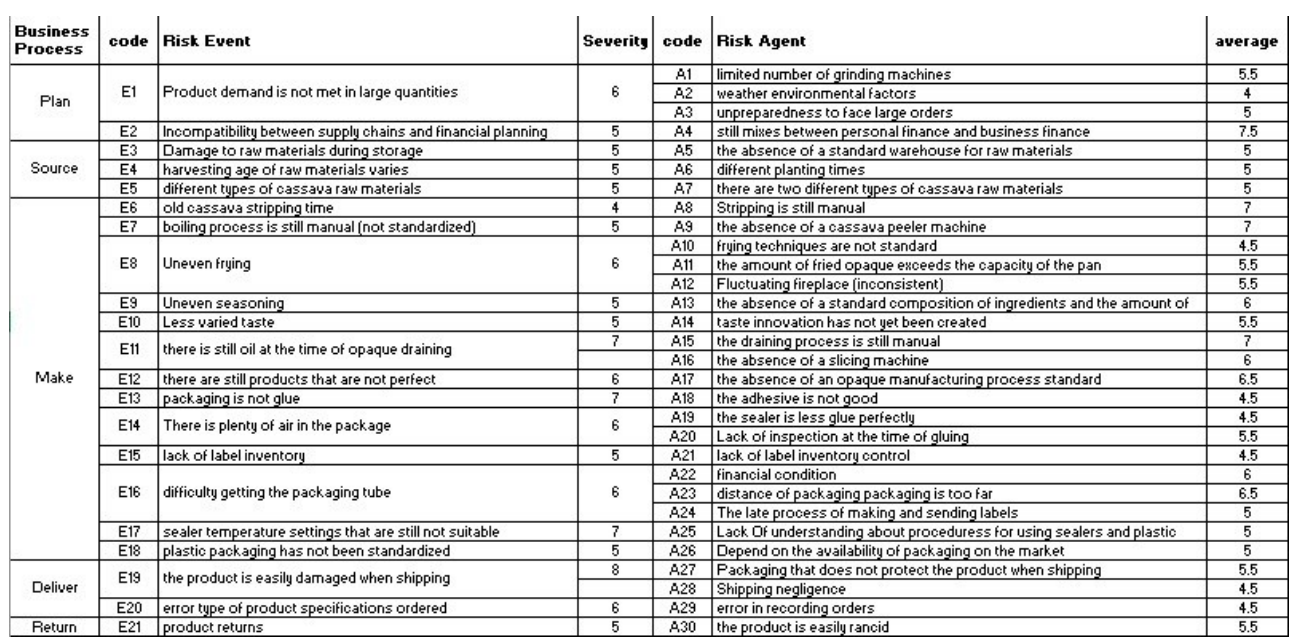

Table 2. House Of Risk (HOR)

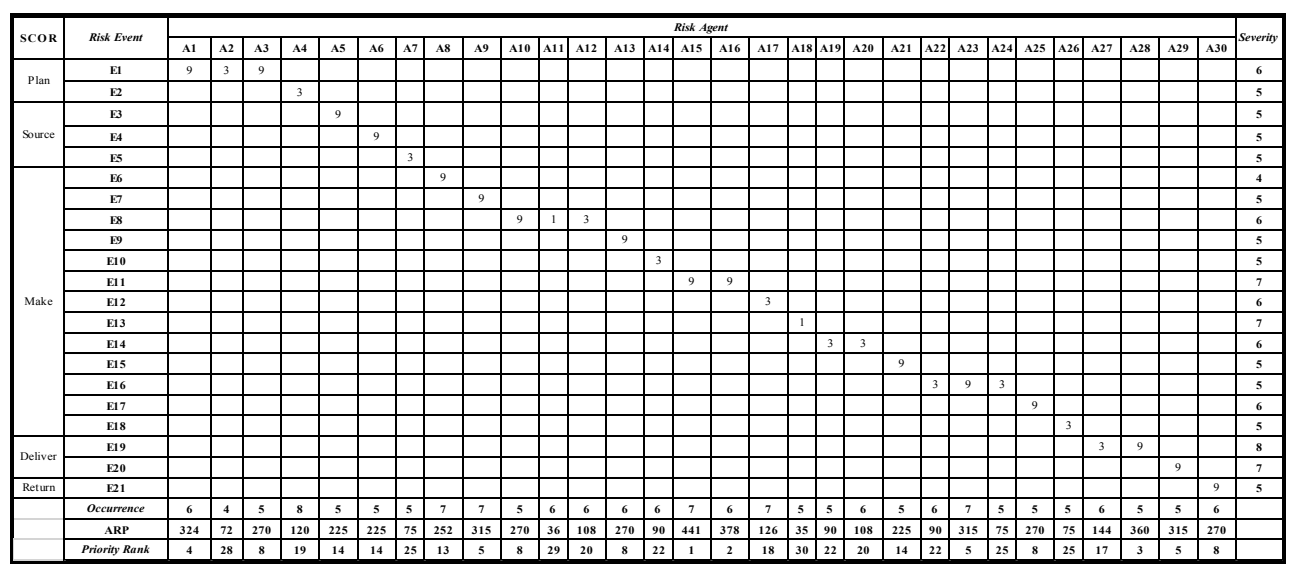




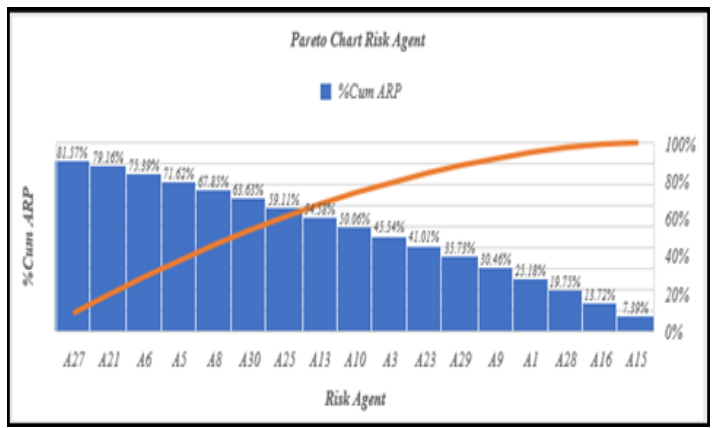

Fig. 1. Pareto risk agent diagram

Table 3 Supply Chain Risk Mitigation

\begin{tabular}{c|l|c} 
Criteria & \multicolumn{1}{|c|}{ Proactive Action } & Code \\
\hline \multirow{2}{*}{ Plan } & Re-layout of Warehouse According to Standards & $\mathrm{P} 1$ \\
\cline { 2 - 3 } & Production Planning Techniques & $\mathrm{P} 2$ \\
\hline \multirow{4}{*}{ Source } & Adding Grinding Machine & $\mathrm{S} 1$ \\
\cline { 2 - 3 } & Spinner Vacuum Machine & $\mathrm{S} 2$ \\
\cline { 2 - 3 } & Cassava Peeler & $\mathrm{S} 3$ \\
\cline { 2 - 3 } & Additional QC Staff & $\mathrm{S} 4$ \\
\hline \multirow{3}{*}{ Make } & Safety Stock and Reorder Point & $\mathrm{M} 1$ \\
\cline { 2 - 3 } & Membuat Standard Operating Procedure (SOP) & $\mathrm{M} 2$ \\
\cline { 2 - 3 } & Making Product Batch According to Product Type & $\mathrm{D} 1$ \\
\hline \multirow{2}{*}{ Deliver } & $\begin{array}{l}\text { Make a cooperation agreement with the Shipping service that } \\
\text { contains a guarantee of product protection guarantee upon delivery }\end{array}$ & $\mathrm{D}$ \\
\hline \multirow{2}{*}{ Return } & &
\end{tabular}

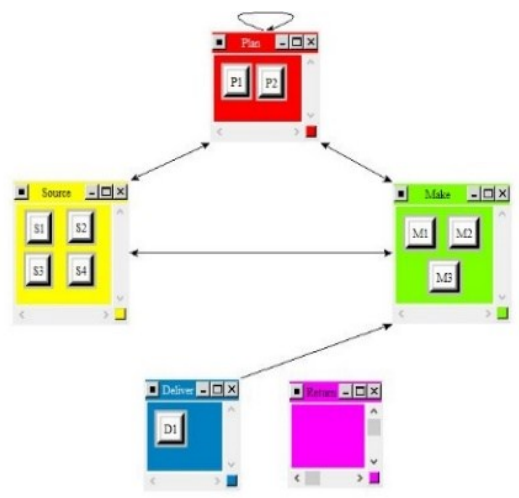

\begin{tabular}{|c|c|c|c|}
\hline \multicolumn{4}{|c|}{ Here are the priorities. } \\
\hline Icon & Name & Normalized by Cluste & Limiting \\
\hline No Icon & P1 & 0.40732 & 0.281565 \\
\hline Nolcon & P2 & 0.59268 & 0.409698 \\
\hline No Icon & s1 & 0.26534 & 0.01467 \\
\hline No Icon & $\$ 2$ & 0.50828 & 0.028115 \\
\hline No Icon & s3 & 0.07521 & 0.004160 \\
\hline Nolcon & $\$ 4$ & 0.15117 & 0.008362 \\
\hline No Icon & M1 & 1.00000 & 0.253423 \\
\hline No Icon & M2 & 0.00000 & 0.000000 \\
\hline No Icon & M3 & 0.00000 & 0.000000 \\
\hline No Icon & D1 & 0.00000 & 0.000000 \\
\hline
\end{tabular}

Fig. 2 ANP model selection of mitigation action on super decision software

From ANP Model Selection of Mitigation Action by using Super Decision Software show that the value results of Normalized by All Element, a priority rating is obtained on the proposed mitigation actions : Production Planning Techniques (P2), Re-layout of Warehouse According to Standards (P1), Safety Stock and Reorder Point (M1), Spinner Vacuum Machine (S2), Adding Grinding Machine (S1), Additional QC Staff (S4), Cassava Peeler Machine (s3), Make a Standard Operating Procedure (SOP) (M2), Making Product Batch According to Product Type (M3), Make a cooperation agreement with the Shipping service that contains a guarantee of product protection guarantee upon delivery (D1) 


\section{Conclusion}

1. Integration HOR and ANP, can be applied to assess the key factors of the risk and the potential risk, determine risk level and risk consequences, and analyze for Supply Chain Risk Mitigation. This integration model HOR and ANP can assign the risk agents base on large aggregate risk potentials, i.e. those with high probability of occurring and causing many risk events with severe impacts and can be used to mitigate supply chain risks and reduce the consequences of risks based on priorities.

2. In the case of the Cassava Opak Chips industry, 21 risk events were identified and had an effect on supply chain risk and there were 17 supply chain risks that needed to be mitigated prioritized.

3. Obtained 10 proposals for supply chain risk mitigation actions in the Cassava Opak chips industry. From the value results of Normalized by All Element, a priority rating is obtained on the proposed mitigation actions namely Production Planning Techniques (P2), Re-layout of Warehouse According to Standards (P1), Safety Stock and Reorder Point (M1), Spinner Vacuum Machine (S2), Adding Grinding Machine (S1), Additional QC Staff (S4), Cassava Peeler Machine (s3), Makea Standard Operating Procedure (SOP) (M2), Making Product Batch According to Product Type (M3), Make a cooperation agreement with the Shipping service that contains a guarantee of product protection guarantee upon delivery (D1).

In the future, it is expected that the processing of opak chips cassava can support the government's roadmap towards Indonesia 4.0 with the fourth industrial revolution (4IR) with one of its initiatives, there is empowering small and medium industries

\section{References}

1. Chopra, Sunil, Meindl, Peter. Supply Chain Management : Strategy, Planning, and Operations, $2^{\text {nd }}$ edition. New Jersey : Prentice-Hall (2004)

2. Pujawan, I.N., Supply Chain Management. First Edition. Institut Teknologi Sepuluh Nopember : Surabaya (2005)

3. Finch, P., Supply Chain Management: An International Journal, Vol. 9 No. 2, pp. 183 96 (2004)

4. Tang CS, Tomlin B. International Journal Production Economic. (116):12-17 (2008)

5. Juttner, U., International Journal of Logistics Management, Vol. 16 No. 1, pp. 120-41 (2005).

6. Zsidisin. International Journal of Supply Chain Management. 5(4):87-197 (2000)

7. Chapman P, Christopher M, Juttner U, Peck,Wilding R. Logistics and Transportation Focus. 4(4):59-63 (2002)

8. Hallikas, Virolainen VM. International Journal of Production Economics. 90(1):47-58 (2004)

9. Norrman A, Lindroth R., Supply chain risk: ashgate Publishing Limited (2004)

10. [SCOR] Supply Chain Operation Reference. Version 10.0 Overview, Supply Chain Council, Pittsburg

11. Pujawan, Geraldin LH. Business Process Management Journal. 15(6):953-67 (2009)

12. Hadiguna. Jurnal Teknik Industri, Vol. 14, No. 1, Juni 2012, 13-24 ISSN 1411-2485 print / ISSN 2087-7439 online (2012)

13. Ulfah, Maria.. "International Journal of Engineering Technology and Scientific Innovation Framework Of Risk Mitigation Of Management Of Refined Sugar Supply 
Chain With The House Of Risk Model.” (4): 400-414 (1851)

14. Ummi, Nurul et al. Jurnal Industrial Servicess 3 (1): 342-50 (2017)

15. Saaty TL. Decision making with dependence and feedback: the analytic network process. Pittsburgh, Pennsylvania: RWS Publications; 0-9620317-9-8.

16. Saaty TL. Fundamentals of the analytic network process. In: ISAHP 1999, Kobe, Japan, (August 12-14; 1999).

17. Saaty, TL. Decision making with the analytic network process (ANP) and its "Super Decisions"' software: The National Missile Defense (NMD) Example. In: ISAHP 2001 Proceedings, Bern, Switzerland, (August 2-4; 2001)

18. Saaty TL. Theory of the analytic hierarchy and analytic network process-examples part 2.2. The International Journal of Systems Research and Information. Technologies (2003:2)

19. Saaty TL. Fundamentals of the analytic network process: dependence and feedback in decision-making with a single network. Journal of Systems Science and Systems Engineering 2004;13(2):129-57. (published at Tsinghua University, Beijing)

20. Saaty TL. Theory and applications of the analytic network process: decision making with benefits, opportunities, costs and risks. Pittsburgh, Pennsylvania: (RWS Publications; 1-888603-06-2)

21. Saaty TL. Rank from comparisons and from ratings in the analytic hierarchy/network processes. European Journal of Operational Research, 168:557-70 (2006)

22. Saaty TL.. Iranian Journal of Operations Research, 1(1):1-27(2008)

23. Lee JW, Kim SH. Using analytic network process and goal programmming for interdependent information system project selection. Computers and Operations Research, 27(4):367-82 (2000)

24. Hafeez K, Zhang Y, Malak N. International Journal of Production Economics, 76(1):39-51 (2002)

25. Karsak EE, Sozer S, Alptekin SE. Product planning in quality function deployment using a combined analytic network process and goal programming approach. Computers and Industrial Engineering, 44(1):171-90 (2003)

26. Niemira MP, Saaty TL. An analytic network process model for financial-crisis forecasting. International Journal of Forecasting, 20(4):573-87(2004)

27. Chung SH, Lee AHI, Pearn WL. International Journal of Production Economics, 96(1):15-36 (2005)

28. Kahraman C, Ertay T, Buyukozkan G. A fuzz. European Journal of Operational Research, 171(2):390-411 (2006)

29. Bayazit O, Karpak B. International Journal of Production Economics, 105(1):79-96 (2007)

30. Aktar DE, Ustun O. Analytic network process and multi-period goal programming integration in purchasing decisions. Computers and Industrial Engineering, 56(2):67790 (2009)

31. Caballero-Luque A, Aragone' s-Beltra'n P, Garc1'a-Melo'n M, Dema-Pe' rezc. International Journal of Information Technology \& Decision Making, 9(3):419-36 (2010)

32. Dagdeviren M, Yuksel I, Kurt M. A fuzzy analytic network process (ANP) model to identify faulty behavior risk (FBR) in work system. Safety Science, 46(5):771-783 (2008) 
33. Saaty TL. Axiomatic foundation of the analytic hierarchy process. Management Science, 32(7):841-55 (1986)

34. Saaty RW. The analytic hierarchy process - what it is and how it is used. Mathematical Modelling, 9(3-5):161-761987, 9:161-76 (1987)

35. Harker P, Vargas L. The theory of ratio scale estimation: Saaty's analytic hierarchy process. Management Science, 33(11):1383-403 (1987)

36. Saaty TL. Some mathematical concepts of the analytic hierarchy process. Behaviormetrika, No.29:1-9 (1991)

37. Liu W. A new method of rectifying judgment matrix. System Engineering-Theory \& Practice, 6:30-4. (in Chinese 1999)

38. Wei CP, Zhang ZM. An algorithm to improve the consistency of a comparison matrix. System Engineering - Theory \& Practice , 8:62-6. (in Chinese 2000)

39. Li H, Ma L. Detecting and adjusting ordinal and cardinal inconsistencies through a graphical and optimal approach in AHP models. Computers \& Operations Research, 34(3):780-98 (2007)

40. Cao D, Leung LC, Law JS. Modifying inconsistent comparison matrix in analytic hierarchy process: a heuristic approach. Decision Support Systems, 44:944-53 (2008) 